\title{
Relationship between serum Vitamin D and insulin resistance in pre- diabetic and diabetic states- A comparative study
}

\author{
Manju. Mi,", Sasmita Mishra ${ }^{2}$, B.D.Toora ${ }^{3}$, S. Vithiyavathy ${ }^{4}$ \\ ${ }^{1}$ Associate Professor, ${ }^{2,3}$ Professor, Dept. of Biochemistry, ${ }^{4}$ Professor, Dept. of General Medicine, Aarupadai \\ Veedu Medical College \& Hospital, Pondicherry
}

*Corresponding Author:

Email: drmanjumay1@gmail.com

\begin{abstract}
Introduction: Pre-diabetes is an important risk factor for the development of overt diabetes as well as cardiovascular disease. Pre-diabetes is frequently associated with obesity which in turn is commonly associated with hypovitaminosis-D. Low Vitamin D levels impair synthesis \& secretion of insulin and through many other mechanisms is attributed in the pathogenesis of diabetes. Pre-diabetes is a stage where prevention efforts have been shown to be effective in delaying or preventing the onset of diabetes. However, there are not many studies that have examined the association between low serum $25(\mathrm{OH})$ Vit D levels and prediabetes. The aim of this study was to compare Vit D levels between the normals, pre-diabetics \& diabetics and study the relationship between insulin resistance and vitamin-D status among individuals with pre-diabetes and diabetes

Materials and Methods: 50 non diabetic, 50 pre-diabetic and 50 type 2 diabetics were included in the study. Waist hip ratio and Body mass index calculated. Fasting blood sugar, insulin, lipid profile, calcium, alkaline phosphatase and serum 25 hydroxy vitamin D were estimated. Insulin resistance (HOMA2-IR) and beta cell function (HOMA2- $\beta$ ) was calculated using HOMA 2 calculator.

Result: Vitamin-D deficiency ( $<20 \mathrm{ng} / \mathrm{ml}$ ) was seen in $20 \%$ normals, $36 \%$ of prediabetics and $48 \%$ of diabetics. BMI, WHR, Total cholesterol, triglycerides, LDL \& VLDL were significantly increased \& HDL decreased in prediabetic and diabetic groups when compared to normals $(\mathrm{p}<0.001) .25 \mathrm{OH}$ Vit $\mathrm{D}$ levels were significantly decreased $(\mathrm{p}<0.0001)$ in diabetics as compared to normals and pre diabetics $(\mathrm{p}<0.0001)$. There was a strong negative correlation between Vit D and HOMA 2-IR in diabetics $(\mathrm{r}=-0.63)$ and prediabetic $(\mathrm{r}=-0.77)$.

Conclusion: Vit D deficiency is common in prediabetic state and subjects having severe vitamin D deficiency $(<10 \mathrm{ng} / \mathrm{ml})$, had the worst insulin resistance. Our study results help in proposing vitamin D levels as an early marker for diabetes and help in recommending vitamin D to be prescribed in the pre diabetic stage itself.
\end{abstract}

Keywords: 25 hydroxy Vitamin D, HOMA 2-IR, Insulin resistance, Obesity, Pre-diabetes.

Received: $01^{\text {st }}$ September, 2017

\section{Introduction}

Diabetes is undoubtedly one of the most challenging health problems in 21 st century. Prediabetes is an important risk factor for the development of overt diabetes as well as cardiovascular disease. ${ }^{1,2}$ Pre-diabetes is defined as impaired fasting glucose (IFG) and/ or impaired glucose tolerance (IGT). Pre-diabetes is an intermediate stage between normal glucose tolerance and type 2 diabetes mellitus. Prediabetes is frequently associated with obesity and other components of metabolic syndrome. Obesity in turn is commonly associated with hypovitaminosis-D due to the capacity of adipose tissue to store $25(\mathrm{OH}) \mathrm{D}$, making it biologically unavailable. ${ }^{3}$ A decreased amount of serum $25(\mathrm{OH}) \mathrm{D}$, calcitriol $\left[1,25(\mathrm{OH})_{2} \mathrm{D}\right]$ and raised parathyroid hormone ( $\mathrm{PTH})$ can increase intracellular calcium in adipocytes, which can stimulate lipogenesis predisposing a patient to further weight gain and thus increasing the risk of diabetes. ${ }^{4}$ Animal studies suggest that low
Accepted: $27^{\text {th }}$ September, 2017

serum $25(\mathrm{OH}) \mathrm{D}$ may impair insulin synthesis and secretion and be involved in the pathogenesis of diabetes. ${ }^{5,6}$ The prevalence of prediabetes is more than type 2 diabetes in all ages, sexes, and race/ethnic groups, in almost all parts of the world. Prediabetes is a stage where prevention efforts have been shown to be effective in delaying or preventing the onset of diabetes. However, there are not many previous studies that have examined the association between serum $25(\mathrm{OH}) \mathrm{D}$ levels and prediabetes especially in Indian population.

Recent research on prevention of diabetes highlights the importance of modifiable risk factors and nutritional factors. One such factor is vitamin $\mathrm{D}$, which is gaining lot of importance. Vitamin D is both a fat-soluble vitamin and a hormone. Researchers have discovered that vitamin D receptors are located all over your body, including the pancreas, which produces insulin and plays a key role in the onset of diabetes. 
Vitamin D deficiency is prevalent in India. Various studies from northern and southern parts of India proved the deficiency of vitamin D in our population. ${ }^{7,8,9}$ Data regarding association of $25(\mathrm{OH}) \mathrm{D}$ with insulin resistance in Indians is very limited. Pittas et al. summarized the role of vitamin D on glucose metabolism. ${ }^{10,11}$ Many Cross sectional and case control studies suggest an inverse association between vitamin D status, glucose intolerance and type 2 diabetes. ${ }^{12,13}$ This could be due the distribution of Vitamin D receptors (VDR) on pancreatic beta cells, adipose tissue and skeletal muscle. Vitamin D status influences insulin secretion or insulin sensitivity. The effect of vitamin D on insulin secretion may be mediated by changes in intracellular calcium concentration in beta cells. $^{14,15}$ Vitamin D improves insulin sensitivity by its anti-inflammatory activity. Vitamin D attenuates the expression of proinflammatory cytokines involved in insulin resistance (IR) such as interleukins, IL-1, IL-6, TNF-a, also down regulates $\mathrm{NF}-\mathrm{Kb}$ (Nuclear factor) activity. ${ }^{16,17}$ Vitamin D deficiency impairs insulin sensitivity by increasing parathyroid hormone (PTH) levels. ${ }^{18,19}$ Many large studies have revealed a higher likelihood of progression of pre-diabetes to diabetes among Vitamin $\mathrm{D}$ deficient subjects. ${ }^{20,21}$ The aims and objectives of this study was 1. To compare serum 25 hydroxy Vitamin D levels between non diabetic, prediabetic and type 2 diabetic subjects and 2. To study the relationship between insulin resistance and vitamin-D status among individuals with pre-diabetes and diabetes

\section{Materials and Methods}

It was a hospital based cross-sectional study done in the Dept. of Biochemistry in our institute. The study was started after getting the approval from the scientific research Committee and ethical committee of the institute. The study subjects included age and sex matched 150 subjects who were divided into three groups - 50 normal (non-diabetic), 50 pre-diabetic subjects and 50 type 2 diabetic subjects. Diabetics and prediabetics were diagnosed based on the ADA 2010 criteria. All the study subjects were selected from the outpatient department of Medicine \& Diabetology by random sampling method. Exclusion criteria included acute or chronic liver, kidney and heart disease, primary hyperparathyroidism, chronic drug use like antiepileptic agents, oral contraceptive pills, steroids which are likely to interfere with vitamin-D metabolism, patients suffering from cancer, pregnant women and individuals with a history of calcium or vitamin-D supplementation in the last one year. The aim of the study and procedures were explained to patients and/or attendant and informed consent was obtained.

Height, weight waist and hip circumferences were measured and BMI \& WHR were calculated using the standard formulas. Blood pressure was recorded using standard mercury sphygmomanometer twice with a gap of 2 hours in rt. arm sitting position (after 10 min rest). Fasting venous blood $(5 \mathrm{ml})$ sample was taken from all the subjects included in the study. The parameters that were measured included FBS, insulin, lipid profile, calcium, ALP and serum 25 hydroxy vitamin D. Insulin resistance in basal state will be calculated using HOMA2-IR (homeostatic model assessment-insulin resistance) and beta cell function was estimated using HOMA2- $\beta$ (22). HOMA2 calculator will be used for calculation. (http://www.dtu.ox.ac.uk) . FBS, lipid profile, calcium and serum ALP were assayed in the fully automated biochemistry analyzer (Chemwell plus, Cpc Company). Serum insulin and $25 \mathrm{OH}$ Vitamin $\mathrm{D}$ were estimated by chemiluminescent immunometric assay (CLIA)

\section{Result}

Statistical analysis of the results was done by $\mathrm{R}$ commander software. Results are presented as mean $\pm 2 \mathrm{SD}$. Statistical significance and difference from control \& test values were evaluated by ANOVA \& Kruskal Wallis test as shown in table I and Figure 1. Correlation coefficient was used to describe the relationship between 25 OH Vitamin D, FBS, BMI, WHR, Total cholesterol, triglycerides, LDL, VLDL, HDL, insulin and insulin resistance as shown in Table II.

Scatter gram was plotted by taking dependent variables on y-axis and independent variable $(25 \mathrm{OH}$ Vit $\mathrm{D})$ on $\mathrm{x}$-axis shown in Figure 2.

Vitamin-D deficiency $(<20 \mathrm{ng} / \mathrm{ml})$ was seen in $20 \%$ of normals, $36 \%$ of prediabetics and $44 \%$ of diabetics. Total cholesterol, triglycerides, LDL, systolic and diastolic blood pressure were significantly increased \& HDL decreased in prediabetic and diabetic groups when compared to normals $(\mathrm{p}<0.001)$. Fasting insulin levels and insulin resistance (HOMA2 IR) were also increased very significantly in prediabetics and diabetics as compared to normals $(\mathrm{p}<0.001)$ and in diabetics as compared to prediabetics. $25 \mathrm{OH}$ Vit D levels were significantly decreased $(\mathrm{p}<0.001)$ in prediabetics and diabetics as compared to normals $(\mathrm{p}<0.001)$.There was no 
significant change in $25 \mathrm{OH}$ Vit D levels between prediabetics and diabetics.

There is no significant difference in HOMA2- $\beta$ (beta cell mass) between the groups.

There was a strong negative correlation between $25 \mathrm{OH}$ Vit D and HOMA 2 IR in diabetics $(r=-0.63)$ and prediabetic $(r=-0.77)$.
Similar strong correlation was found between 25 $\mathrm{OH}$ Vit $\mathrm{D}$ and fasting insulin levels in diabetics $(\mathrm{r}=-0.52)$ and prediabetic $(\mathrm{r}=-0.76) .25 \mathrm{OH} \mathrm{Vit}$ $\mathrm{D}$ had strong negative correlation with FBS in diabetics $(\mathrm{r}=-0.58)$ and prediabetic $(\mathrm{r}=-0.66)$, systolic BP( $\mathrm{r}=-0.44)$ and diastolic BP $(-0.46)$ in diabetics.

Table 1: Comparison of various anthropometric and biochemical parameters in normal, prediabetics and diabetic groups

\begin{tabular}{|l|c|c|c|}
\hline \multicolumn{1}{|c|}{ Parameters } & Normals $(\mathbf{n = 5 0})$ & Pre diabetics(n=50) & Diabetics(n=50) \\
\hline Age(yrs) & $48.5 \pm 20.1$ & $50.1 \pm 17.4$ & $50.9 \pm 18.2$ \\
\hline Systolic BP(mm Hg) & $122 \pm 10.9$ & $138.4 \pm 7.5 *$ & $140 \pm 12.2^{*}$ \\
\hline Diastolic BP(mm Hg) & $80.4 \pm 5.5$ & $90.8 \pm 5.9^{*}$ & $93.2 \pm 8.3^{*}$ \\
\hline BMI & $25.2 \pm 2.01$ & $26.8 \pm 2.39$ & $27.7 \pm 2.41$ \\
\hline WHR & $0.742 \pm 0.13$ & $0.819 \pm 0.07$ & $0.905 \pm 0.127 *$ \\
\hline FBS $(\mathrm{mg} / \mathrm{dl})$ & $87.24 \pm 7.8$ & $108.6 \pm 9.5$ & $144.6 \pm 44^{*}+$ \\
\hline $\begin{array}{l}\text { Total Cholesterol } \\
\text { (mg/dl) }\end{array}$ & $161 \pm 16.1$ & $187.3 \pm 11.65^{*}$ & $207.1 \pm 33.98^{*}$ \\
\hline TGL $(\mathrm{mg} / \mathrm{dl})$ & $103.4 \pm 15.05$ & $128.6 \pm 20^{*}$ & $173.7 \pm 31.08^{* \dagger}$ \\
\hline HDL $(\mathrm{mg} / \mathrm{dl})$ & $43.5 \pm 6.25$ & $37.2 \pm 4.42^{*}$ & $33.9 \pm 6.36^{*}$ \\
\hline LDL $(\mathrm{mg} / \mathrm{dl})$ & $96.8 \pm 0.55$ & $124 \pm 13.5^{*}$ & $138 \pm 33^{*}$ \\
\hline S. Calcium $(\mathrm{mg} / \mathrm{dl})$ & $9.94 \pm 0.55$ & $9.83 \pm 0.56$ & $9.52 \pm 0.47$ \\
\hline F. Insulin( $\mu \mathrm{IU} / \mathrm{ml})$ & $7.58 \pm 1.85$ & $12.62 \pm 2.96^{*}$ & $18.88 \pm 2.93^{*} \dagger$ \\
\hline 25 OH Vit D $(\mathrm{ng} / \mathrm{ml})$ & $26.2 \pm 5.12$ & $19.9 \pm 3.31^{*}$ & $19.2 \pm 5.42^{*}$ \\
\hline HOMA 2-IR & $1.65 \pm 0.5$ & $3.43 \pm 1.04^{*}$ & $6.89 \pm 3.1 * \dagger$ \\
\hline HOMA-B & $121.39 \pm 39$ & $100.46 \pm 16.5$ & $97.7 \pm 36$ \\
\hline
\end{tabular}

$* p<0.001$ as compared to normals; $\dagger p<0.001$ as compared to prediabetics

Data is expressed as mean $\pm \mathrm{SD}$

Table 2: Univariate analysis by spearman linear regression

\begin{tabular}{|l|c|c|c|c|}
\hline \multicolumn{1}{|c|}{ Parameters } & $\begin{array}{c}\text { Parameter } \\
\text { adjusted for }\end{array}$ & $\begin{array}{c}\text { Correlation } \\
\text { coefficient(r) } \\
\text { Total }\end{array}$ & $\begin{array}{c}\text { Correlation } \\
\text { coefficient(r) } \\
\text { Prediabetics }\end{array}$ & $\begin{array}{c}\text { Correlation } \\
\text { coefficient(r) } \\
\text { Diabetics }\end{array}$ \\
\hline VIT D \& FBS & BMI & -0.59 & -0.66 & -0.58 \\
\hline $\begin{array}{l}\text { VITD \& } \\
\text { HOMA2 IR }\end{array}$ & BMI & -0.63 & -0.77 & -0.63 \\
\hline $\begin{array}{l}\text { VIT D \& } \\
\text { INSULIN }\end{array}$ & BMI & -0.62 & -0.76 & -0.52 \\
\hline VIT D \& SBP & BMI & -0.50 & - & -0.44 \\
\hline VIT D \& DBP & BMI & -0.52 & - & -0.47 \\
\hline
\end{tabular}

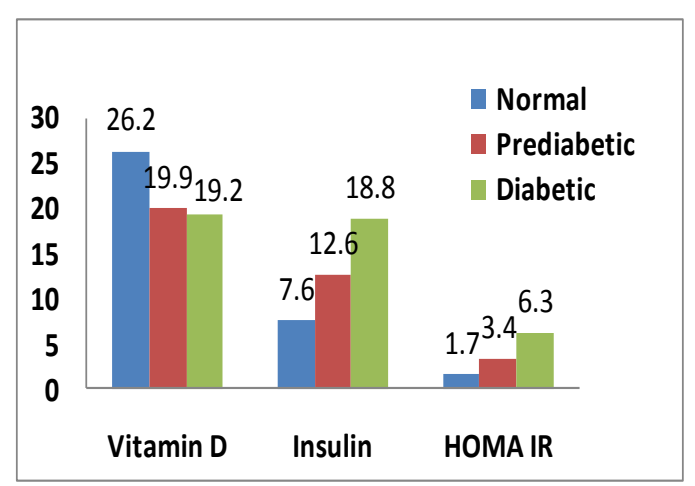

Fig. 1: Comparison of Vitamin D, Insulin and HOMA IR in normal, pre-diabetic and diabetic groups 


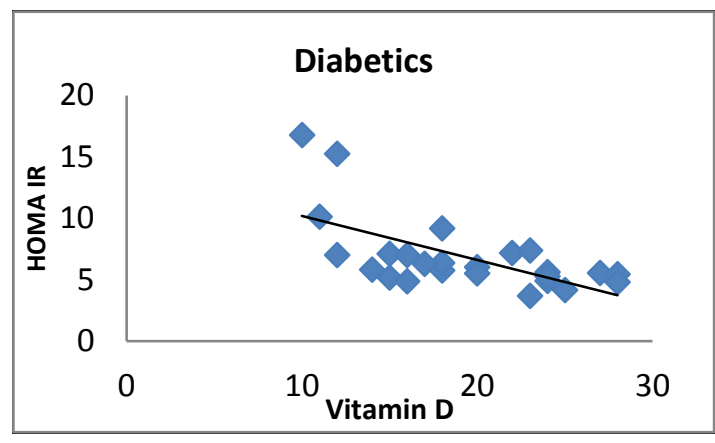

Fig. 2: Correlation between vitamin D and HOMA-IR in diabetic group

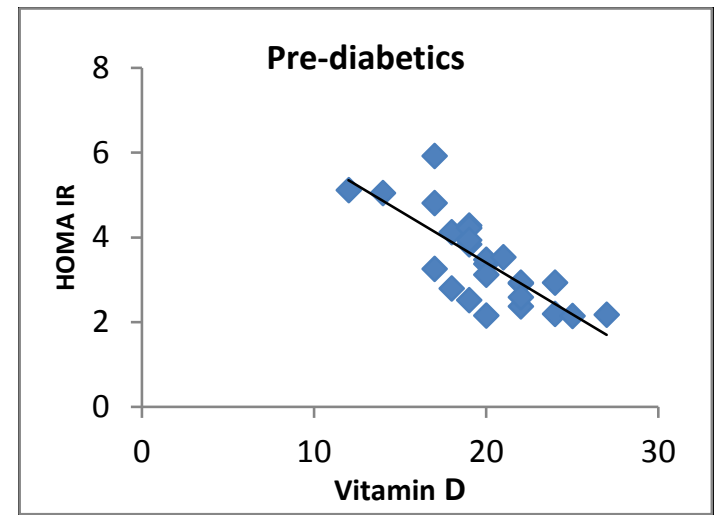

Fig 3: Correlation between vitamin D and HOMA-IR in pre-diabetic group

\section{Discussion}

Our study showed that vitamin-D insufficiency/deficiency was common among individuals with prediabetes. In our study, among individuals with prediabetes, those having severe vitamin D deficiency $(<10 \mathrm{ng} / \mathrm{ml})$, had the worst insulin resistance (HOMA2-IR,) as compared to those having higher levels, with an inverse correlation between vitamin-D status and insulin resistance after adjusting for BMI. Adjustment for BMI was done because vitamin$\mathrm{D}$ which is mainly stored in the adipose tissue will be lower in the serum for individuals with higher BMI. Our study results support the idea that Vitamin-D deficiency/insufficiency may have some role in the development/worsening of insulin resistance in individuals with prediabetes in our country. Hence many longitudinal prospective studies are needed to assess whether this worsened insulin resistance in prediabetes individuals with lower vitamin-D actually results in increased progression to diabetes. Scragg et al reported $25(\mathrm{OH}) \mathrm{D}$ to be significantly lower in individuals with newly diagnosed IGT or diabetes as compared to normal individuals. ${ }^{12}$ In our study, vitamin-D levels were not significantly different in individuals with pre-diabetes as compared to those with diabetes but were significantly more as compared to normals. Many studies showed that vitamin D levels were more closely linked to blood sugar levels than BMI. Those studies showed that obese people who didn't have diabetes or related disorders had higher vitamin D levels than those with diabetes. Lean people with diabetes or related disorders were more likely to have low vitamin D levels than those without such disorders. So our study results support the idea that Vit D levels are closely associated with insulin resistance than with obesity.

Our study results showed a strong negative correlation between Vit D levels and insulin resistance, HOMA 2 IR in prediabetics $(r=-0.77)$ and diabetics $(\mathrm{r}=-0.63)$. Our study mainly concentrates on the pre-diabetes people as it is the precursor of diabetes. Some recent studies showed that vitamin D may influence insulin sensitivity by acting on target cells of insulin action as well as on the beta cells of pancreas. Vitamin D could increase number of insulin receptors, enhance the activity of transcription factors, and regulate the cell calcium concentration thus improve insulin sensitivity. ${ }^{23,24}$ Inflammation is one of the important physiopathologic mechanisms. Vitamin D could regulate the immunological reaction of macrophages and monocytes reduce 
the concentration of interleukin-1 (IL-1), interleukin-6 (IL-6), and tumor necrosis factor$\alpha(\mathrm{TNF}-\alpha)$, and so on, and thereby relieve inflammatory reaction. ${ }^{25}$ Several researches who have studied the interaction between vitamin $\mathrm{D}$ and $\beta$-cell function showed that $\beta$-cells express vitamin $\mathrm{D}$ receptor, which can bind to 1,25 dihydroxyvitamin D. There is vitamin D acting element in insulin gene promoter region, and vitamin $\mathrm{D}$ can activate the transcription of insulin gene. ${ }^{23,26}$ These studies suggested that vitamin $\mathrm{D}$ promotes insulin synthesis and secretion. Meanwhile, $\beta$-cells express 25-OHD-1 alpha-hydroxylase (CYP27B1), which could facilitate vitamin $D$ activation. Vitamin $D$ can also regulate $\beta$-cell calcium concentration and influence insulin secretion through calciumdependent pathway. ${ }^{27}$

Considering the association between vitamin $\mathrm{D}$ and insulin sensitivity and $\beta$-cell function, Vitamin D supplement may be one promising way to improve insulin resistance and reduce risk of diabetes. Studies conducted by Mitri et al, ${ }^{27} \mathrm{P}$. R. von Hurst etal and many other studies suggested various dosages of 25-hydroxy vitamin D supplements in people with Vit D deficiency to improve insulin resistance and prevent or delay the progression of diabetes. But the dose of Vit D supplementation still differs from region to region. Hence would suggest many Vit D supplementation prospective studies to be done in our country.

Our study shows a strong correlation between $25 \mathrm{OH}$ Vit D and fasting insulin levels in diabetics $(\mathrm{r}=-0.52)$ and prediabetic $(\mathrm{r}=-0.76)$. $25 \mathrm{OH}$ Vit $\mathrm{D}$ had strong negative correlation with FBS in diabetics $(\mathrm{r}=-0.58)$ and prediabetic $(\mathrm{r}=-0.66)$, systolic $\mathrm{BP}(\mathrm{r}=-0.44)$ and diastolic BP $(-0.46)$ in diabetics. It indirectly implies relation of Vit $\mathrm{D}$ with development of metabolic syndrome, which is one of the most common causes of cardiovascular complications.

As our study results show there is a decline in Vit D levels in prediabetic stage itself, we would like to propose Vit D levels to be assessed routinely in pre diabetics and suggest Vit D supplementation for all pre-diabetic people. Hence we can prevent or delay the progression of insulin resistance and hence all the diabetic complications mainly cardiovascular complications which are mainly due to increased insulin resistance. Further studies can be planned which may help in proposing Vit D levels as a criteria for diagnosis of metabolic syndrome.

\section{Conclusion}

Vit $\mathrm{D}$ deficiency is common in prediabetic state and subjects having severe vitamin D deficiency $(<10 \mathrm{ng} / \mathrm{ml})$, had the worst insulin resistance. Our study results help in strongly proposing vitamin D levels as an early marker for diabetes and help in recommending vitamin $\mathrm{D}$ to be prescribed in the pre diabetic stage itself.

\section{References}

1. Schmidt MI, Duncan BB, Bang H, Pankow JS, Ballantyne CM, Golden SH, Folsom AR, Chambless LE: Identifying individuals at high risk for diabetes: the atherosclerosis risk in communities study. Diabetes Care 2005;28(8):2013-8.

2. Levitzky YS, Pencina MJ, D'Agostino RB, Meigs JB, Murabito JM, Vasan RS, Fox CS: Impact of impaired fasting glucose on cardiovascular disease: the framingham heart study. J Am Coll Cardiol 2008;51(3):264-70.

3. Palomer X, Gonzalez-Clemente JM, Blanco-Vaca F, Mauricio 5. D. Role of vitamin D in the pathogenesis of type 2 diabetes mellitus. Diabetes Obes Metab 2008;10:185-97.

4. Takiishi T, Gysemans C, Bouillon R, Mathieu C. 6. Vitamin D and diabetes. Endocrinol Metab Clin North Am 2010;39:419-46.

5. C. Mattila, P. Knekt, S. M“annist"o et al. Serum 25-hydroxyvitamin D concentration and subsequent risk of type 2 diabetes. Diabetes Care 2007;30:2569-70.

6. S. Lim, M. J. Kim, S. H. Choi et al., Association of vitamin D deficiency with incidence of type 2 diabetes in high-risk Asian subjects1-4. American Journal of Clinical Nutrition 2013;97:524-30.

7. Harinarayan CV, Gupta N, Kochupillai N. Vitamin D status in primary hyperparathyroidism in India. Clin Endocrinol 1995;43:351-8.

8. Goswami R, Gupta N, Goswami D, Marwaha RK, Tandon N, Kochupillai N. Prevalence and significance of low 25-hydroxy vitamin D concentration in healthy subjects in Delhi. Am J Clin Nutr 2000;72:472-75.

9. Harinarayan CV, Ramalakshmi T, Prasad UV, Sudhakar D. Vitamin D status in Andhra Pradesh: a population based study. Indian $\mathrm{J}$ Med Res 2008;127:211-8.

10. Chiu KC, Chu A, Go VLW, Saad MF. Hypovitaminosis $\mathrm{D}$ is associated with insulin resistance and b cell dysfunction. Am J Clin Nutr 2004;79:820-5.

11. Pittas AG, Lau J, Hu FB, Dawson-Hughes B. The role of vitamin $\mathrm{D}$ and calcium in type 2 diabetes. A systematic review and metaanalysis. J Clin Endocrinol Metab 2007;92:2017-29.

12. Scragg R, Sowers M, Bell C. Serum 25-hydroxy vitamin $\mathrm{D}$, diabetes and ethnicity in the third national health and nutrition examination survey. Diabetes Care 2004;27:2813-8.

13. Ford ES, Ajani UA, McGuire LC, Liu S. Concentration of serum vitamin D and the metabolic syndrome among US adults. Diabetes Care 2005;28:1228-30. 
14. Bourlon PM, Billaudel B. Dussert. Influence of Vitamin D3 deficiency and 1, 25 di hydroxy D3 on denovo insulin biosynthesis in islets of the rat endocrine pancreas. J Endocrinol 1999; 160:8795.

15. Danescu LG, Levy S, Levy J. Vitamin D and diabetes mellitus. Endocrine 2009;35:11-7.

16. Giulietti A, Van Etten E, Overbergh L, Stoffels K, Bouillon R,Mathieu C. Monocytes from type 2 diabetic patients have a pro-inflammatory profile: 1,25-dihydroxy vitamin D3 works as anti inflammatory. Diabetes Res Clin Pract 2007;77(1):47-57.

17. Cohen-Lahav M, Douvdevani A, Chaimovitz C, Shany S. The anti inflammatory activity of 1,25 dihydroxy vitamin D3 in macrophages. J Steroid Biochem Mol Biol 2007; 103:558-62.

18. Saxe AW, Gibson G, Gingerich RL, Levy J. Parathyroid hormone decreases in vivo insulin effect on glucose utilization. Calcif Tissue Int 1995;57:127-32.

19. Teegarden D, Donkin SS. Vitamin D: emerging new roles in insulin sensitivity. Nutr Res Rev. 2009;22:82-92.

20. Deleskog A, Hilding A, Brismar K, Hamsten A, Efendic S, Östenson CG. Low serum 25-hydroxy vitamin D level predicts progression to type 2 diabetes in individuals with prediabetes but not with normal glucose tolerance. Diabetologia 2012;55:1668-78

21. Forouhi NG, Luan J, Cooper A, Boucher BJ, Wareham NJ. Baseline serum 25-hydroxy Vitamin D is predictive of future glycemic status and insulin resistance: The Medical Research Council Ely Prospective Study 1990- 2000. Diabetes 2008;57:2619-25.

22. Levy JC, Matthews DR, Hermans MP. Correct homeostasis model assessment (HOMA) evaluation uses the computer program. Diabetes Care 1998;21:2191-2.

23. B. Maestro, S. Molero, S. Bajo, N. Dávila, and C. Calle. Transcriptional activation of the human insulin receptor gene by 1, 25-dihydroxyvitamin D3. Cell Biochemistry and Function 2002;20(3):227-32

24. T. W. Dunlop, S. Väisänen, C. Frank et al. The human peroxisome proliferator-activated receptor $\delta$ gene is a primary target of $1 \alpha, 25$ dihydroxyvitamin D3 and its nuclear receptor. Journal of Molecular Biology 2005;349(2):24860

25. M. Cohen-Lahav, S. Shany, D. Tobvin, C. Chaimovitz, and A. Douvdevani. Vitamin D decreases NFKB activity by increasing I $\mathrm{B} \alpha$ levels. Nephrology Dialysis Transplantation 2006;21(4):889-97.

26. J. A. Johnson, J. P. Grande, P. C. Roche, and R. Kumar. Immunohistochemical localization of the $1,25(\mathrm{OH}) 2 \mathrm{D} 3$ receptor and calbindin D28k in human and rat pancreas. AM.J.PHYSIOL. 1994;267(3) 356-60

27. J. Mitri, B. Dawson-Hughes, F. B. Hu, and A. G. Pittas. Effects of vitamin D and calcium supplementation on pancreatic $\beta$ cell function, insulin sensitivity, and glycemia in adults at high risk of diabetes: the Calcium and Vitamin D for Diabetes Mellitus (CaDDM) randomized controlled trial. American Journal of Clinical Nutrition 2011;94(2):486-94. 